\title{
TINDAK TUTUR LANGSUNG TIDAK LITERAL PADA KELUARGA BATIH YANG BERBAHASA MELAYU MANADO
}

\author{
Grace Shirley Luntungan \\ Fakultas Bahasa dan Seni Universitas Negeri Manado \\ Korespondensi: Kampus Unima di Tondano Minahasa 95618 \\ Pos-el: grace_luntungan@yahoo.fr
}

\begin{abstract}
Abstrak
Tindak Tutur Langsung Tidak Lateral pada Keluarga Batih yang Berbahasa Melayu Manado. Komunikasi dalam lingkungan keluarga Batih yang berbahasa Melayu Manado tidak terlepas dari tindak tutur langsung tidak literal. Bentuk tindak tutur dan maksud dari penutur dapat menimbulkan tanggapan atau reaksi yang berbeda-beda. Setiap tindak tutur dapat mencerminkan banyak hal. Penelitian ini bertujuan untuk mendeskripsikan tindak tutur langsung tidak literal pada keluarga Batih yang berbahasa Melayu Manado, dan menjelaskan cerminan dari tindak tutur yang muncul dalam komunikasi di lingkungan keluarga Batih. Metode penelitian yang digunakan adalah metode kualitatif dalam bentuk studi kasus pada sebuah keluarga Batih yang terdiri dari ayah, ibu, anak laki-laki dan anak perempuan. Hasil penelitian menunjukkan bahwa tindak tutur langsung tidak literal muncul dalam bentuk kalimat berita, kalimat perintah dan kalimat tanya. Tuturan yang menggunakan kata kita dan ngana mencerminkan dua corak relasi di antara sesama anggota keluarga Batih, yakni corak relasi egaliter dan corak relasi hierarkhis.
\end{abstract}

Kata kunci: Tindak tutur langsung tidak literal, keluarga Batih,

Bahasa Melayu Manado

\begin{abstract}
Direct Nonliteral Speech Act in the Nuclear Family that Uses Manado Malay. Communication within the nuclear family that uses Manado Malay cannot be disengaged from the direct nonliteral speech act. The form of speech acts and the intention of the speaker could cause a different response or reaction. Each speech act can reflect many things. This study aims to describe the direct nonliteral speech act in the nuclear family that uses Manado Malay, and to explains the reflection of speech acts that may appear in daily communication among the nuclear family. The research method used is qualitative method in form of case study for a nuclear family which consists of father, mother, son and daughter. The results show that the direct nonliteral speech act are appeared in affirmative sentences, imperative sentences and interrogative sentences. The speech act using the word "kita" and "ngana" reflects two styles of relationship among the nuclear family. Those are the egalitarian relationship and hierarchic relationship.
\end{abstract}

Keywords: Direct nonliteral speech act, nuclear family, Manado Malay 


\section{PENDAHULUAN}

Fungsi utama bahasa yaitu sebagai sarana untuk mengomunikasikan informasi, baik pikiran, perasaan, keinginan, maupun maksud, sekaligus menjalin hubungan yang baik di antara manusia sebagai pengguna bahasa. Setiap informasi dapat muncul dalam berbagai bentuk tuturan. Bentuk tuturan pun dapat dipahami sebagai tindakan yang disebut tindak tutur, karena tuturan seseorang dapat mengandung maksud yang lain dari apa yang dituturkan.Tindak tutur muncul dalam berbagai ranah/domain dalam ekspresi berbahasa.Tindak tutur merupakan satuan analisis pragmatik, yaitu cabang ilmu bahasa yang mengkaji penggunaan bahasa dari segi makna yang dikaitkan dengan situasi tutur (Trudgill, $2003: 125$ ).

Keluarga Batih merupakan salah satu ranah/ domain dalam mengekspresikan bahasa. Banyak hal menarik untuk dikaji sehubungan dengan tindak tutur dari setiap anggota keluarga yang ada, dalam hal bentuk, maksud, serta cerminan dari setiap tuturan yang muncul.Keluarga Batih merupakan unit sosial terkecil yang terdiri dari seorang suami, seorang isteri dan anak atau anakanak yang belum kawin. Dalam hal ini peneliti merasa tertarik untuk mengkaji tuturan-tuturan yang dikategorikan sebagai salah satu jenis tindak tutur yakni tindak tutur langsung tidak literal dalam bahasa melayu Manado.

Bahasa Melayu Manado (BMM) merupakan Lingua Franca yang digunakan di seluruh daerah di Sulawesi Utara. Bahasa ini dipergunakan untuk komunikasi lisan. Tidak ada standar ortografi/tulisan yang pernah disahkan. BMM meluas pemakaiannya hingga di Sulawesi Tengah dan Papua walaupun sudah ada pengaruh dialek regional. Sebagian besar kata-kata dalam BMM sama seperti kata-kata dalam bahasa Indonesia. Namun dalam situasi tidak formal, BMM lebih mendominasi bahasa Indonesia. Bahkan BMM mulai menggeser bahasa-bahasa daerah di Minahasa (Tallei, 2007). Dibuktikan pada kalangan anak-anak hingga orang dewasa hampir semuanya menggunakan BMM sebagai bahasa pertama dalam berkomunikasi. Mereka yang menggunakan BMM sebagai bahasa kedua biasanya di kalangan orang-orang tua yang tinggal di daerah pedesaan.

Di dalam lingkungan keluarga Batih sering muncul tuturan-tuturan yang menimbulkan pemahaman lain bagi pendengar atau mitra tutur, namun bagi mitra tutur yang tahu situasi tutur dapat memahami maksud dan tujuan penutur. Contoh, pada pagi hari pukul 7 dalam situasi ketika anak-anak akan berangkat ke sekolah, ayah yang sudah lama menunggu di mobil berkataMasih fruk kwa' ini, sadiki le baru mo pigi"Masih terlalu pagi untuk pergi ke sekolah, tunggu sebentar lagi”.

Tujuan tuturan yaitu apa yang diinginkan penutur dapat dipahami oleh mitra tutur. Dengan kata lain, tindak tutur berhasil dalam menjalin hubungan interpersonal yang dimaksudkan oleh penutur sejauh tindak tutur tersebut dapat menimbulkan efek ilokusi terhadap mitra tuturnya (Habermas dalam Cummings, 2007:287). Setiap tuturan mengandung maksud dan tujuan penutur. Seperti dalam tuturan di atas, bagi orang lain yang mendengar tentu akan memahami bahwa memang belum saatnya berangkat ke sekolah, tetetapi bagi penutur waktunya sudah sangat kasip dan harus segera berangkat.Tuturan tersebut dapat dikategorikan sebagai tindak tutur langsung tidak literal, karena menunjukkan tindak tutur yang diutarakan dengan modus kalimat yang sesuai dengan maksud tuturan, tetetapi kata-kata yang menyusunnya tidak memiliki makna yang sama dengan maksud penuturnya (lihat Wijana, 1996:35). Hal ini tentu sangat menarik untuk dikaji dalam lingkungan keluarga Batih, misalnya bentuk tindak 
tutur yang muncul, pemahaman terhadap tindak tutur baik ayah terhadap ibu, begitu sebaliknya ibu terhadap ayah, atau ibu terhadap anak, ayah terhadap anak, anak terhadap ibu atau ayah, bahkan di antara anak-anak, sekaligus untuk memahami sepenuhnya hakekat komunikasi dalam keluarga itu sendiri.

Berdasarkan hal-hal yang telah dikemukan sebelumnya, maka penulis memilih untuk meneliti tindak tutur langsung tidak literal pada keluarga Batih yang berbahasa melayu Manado, dengan tujuan untuk mendeskripsikan bentukbentuk tindak tutur langsung tidak literal BMM yang muncul dalam komunikasi di lingkungan keluarga Batih, serta menjelaskan cerminan dari tindak tutur yang muncul.

Diharapkan dengan adanya penelitian ini akan memberikan kontribusi terhadap teori tindak tutur, karena hasil penelitian tindak tutur langsung tidak literal BMM pada dasarnya memiliki kesamaan dengan teori-teori tindak tutur pada umumnya. Selanjutnya dapat memberikan kontribusi terhadap pemahaman konteks dimana berlangsung tindak tutur langsung tidak literal, karena ternyata hasil penelitian ini menunjukkan pentingnya konteks dalam memaknai maksud tuturan penutur yang pada akhirnya dapat memberikan pengaruh terhadap mitra tutur untuk melakukan maksud tuturan tersebut (bandingkan Nadar, 2009 : 15). Penelitian ini juga diharapkan dapat memberikan kontribusi terhadap konsep corak relasi dalam keluarga Batih yang berBMM, karena hasil penelitian menunjukkan corak relasi di antara anak-anak, ayah dengan ibu, serta relasi antara anak-anak dengan orang tua, selain itu akan menjadi kepentingan dokumentasi dalam upaya pelestarian BMM, serta menjadi bahan pertimbangan bagi pemerintah daerah / pengambil kebijakan untuk menetapkan standar ortografi/tulisan BMM. Penelitian ini diharapkan juga dapat menjadi bahan bandingan bagi peneliti bahasa pada bahasa-bahasa yang lain, atau pada ranah/domain ekspresi berbahasa yang lain juga, serta dapat digunakan oleh masyarakat luas yang ingin mengetahui konsep hidup keluarga Batih yang menggunakan BMM. Tindak tutur langsung tidak literal paling banyak dijumpai di keluarga Batih, dan ini menjadi model untuk relasi-relasi akrab antara teman atau kolega.

\section{METODE}

Metode penelitian yang digunakan yaitu metode deskriptif kualitatif dalam bentuk studi kasus pada sebuah keluarga Batih. Penelitian kualitatif menurut Bogdan dan Taylor (dalam Moleong, 2007:3) merupakan prosedur penelitian yang menghasilkan data deskriptif berupa kata-kata tertulis maupun lisan dari orangorang dan perilaku yang diamati. Pendekatan ini diarahkan pada latar dan individu tersebut secara holistik (utuh).

Studi kasus bukanlah sebuah pilihan metodologis, namun lebih sebagai pilihan objek yang diteliti. Peneliti memilih untuk meneliti (atau melakukan studi) kasus (Stake, 2009:299). Sebagai penelitian studi kasus, maka tempat penelitian yang dipilih yaitu satu keluarga Batih yang terdiri dari ayah, ibu, anak lelaki, dan anak perempuan yang bertempat tinggal di kota Manado. Keluarga Batih yang dipilih ini terdiri dari orang tua PNS dengan anak-anak remaja putra dan putri.Mereka dipilih karena anak-anak sudah cukup paham tentang konteks dan kondisi hidup keluarga, lewat sosialisasi primer, sehingga tuturan langsung tidak literal dari masing-masing anggota cepat dipahami.

Sebagai penelitian yang bersifat deskriptif kualitatif, maka tidak digunakan istilah sampel penelitian melainkan objek penelitian (Chaer, 2007:42).Objek penelitian ini adalah tuturan-tuturan dalam bahasa Melayu Manado dari satu keluarga Batih (ayah, ibu, dan anak-anak) 
sebagai studi kasus. Keluarga ini terdiri atas 4 orang yang dalam pembahasan digunakan peristilahan teknis antropologis secara internasional yaitu $\mathbf{F}=$ untuk ayah (= Father), $\mathbf{M}=$ untuk ibu (= Mother), $\mathbf{S}=$ untuk anak lelaki (= Son), dan $\mathbf{D}=$ untuk anak perempuan (= Daughter). $\mathbf{S}$ sebagai kakak dan D sebagai adik.

Tuturan-tuturan yang muncul dalam aktivitas sebelum berangkat ke kantor maupun sebelum berangkat ke sekolah itulah yang menjadi objek penelitian begitu juga tuturan-tuturan yang muncul ketika semua anggota keluarga sudah kembali ke rumah yakni anak-anak yang sudah pulang dari sekolah dan ayah serta ibu yang sudah kembali dari kantor.

Teknik penyediaan data juga mengikuti konsep Sudaryanto (1993:133136). Di dalam hal ini peneliti menyimak seluruh tuturan-tuturan spontan yang digunakan dalam situasi keluarga seharihari tanpa terlibat dalam konversasi (teknik simak bebas libat cakap).Selain itu digunakan teknik pengumpulan data yang dikemukakan oleh Stake (2009:307) yaitu teknik triangulasi data dengan proses check-recheck untuk mengurangi kemungkinan terjadinya kesalahan interpretasi, berupa penggunaan prosedurprosedur yang beragam termasuk pengumpulan data hingga mencapai titik jenuh (redundancy of data gathering).

Data yang diperoleh dianalisis sesuai dengan tujuan penelitian yang telah ditetapkan sebelumnya yakni dengan menggunakan teknik pilah unsur penentu yang disebut daya pilah pragmatis.

Tuturan-tuturan yang muncul dikelompokkan, selanjutnya dipilah sesuai dengan reaksi keterdengaran dan kadar keterdengaran dari masing-masing mitra tutur terhadap tuturan-tuturan tersebut yang disebut sebagai tindak tutur langsung tidak literal, lalu diberi makna, dan dijelaskan tentang pemahaman terhadap tindak tutur di antara peserta tutur (penutur kepada mitra tutur), serta diuraikan hal-hal yang menjadi cerminan dari tindak tutur yang muncul dalam komunikasi di lingkungan keluarga Batih, kemudian ditarik kesimpulan dari semua uraian/penjelasan tersebut.

\section{HASIL DAN PEMBAHASAN}

Berikut ini disajikan tuturantuturan yang termasuk jenis tindak tutur langsung tidak literal yang muncul dalam komunikasi pada keluarga Batih yang berBMM. Data yang disajikan ini dianggap representative, artinya cukup lazim dijumpai di banyak keluarga Batih.

Data yang diperoleh dipilah berdasarkan metode pilah pragmatis dan disesuaikan dengan tolok ukur yang dibahas sebelumnya.

\section{Bentuk-bentuk Tindak Tutur Langsung Tidak Literal}

Berikut ini bentuk-bentuk tindak tutur langsung tidak lateral disajikan berupa tabel.

Tabel 1.

Bentuk-bentuk tindak tutur langsung tidak lateral

\begin{tabular}{|l|l|l|}
\hline & \multicolumn{1}{|c|}{ Tuturan-tuturan } & \\
No. & \multicolumn{1}{|c|}{ Siapa kepada Siapa } \\
\hline 1. & Soitukwa' bangun lat! & $\mathrm{M} \longrightarrow \mathrm{SD}$ \\
2. & Iyo, manyao kamari ngana pa Mama! & $\mathrm{M} \longrightarrow \mathrm{D}$ \\
3. & Nda' mo mandi ngoni? & $\mathrm{F} \longrightarrow \mathrm{SD}$ \\
4. & Iyo, tidor-tidor jo nanti sosapu malayang! & $\mathrm{M} \longrightarrow \mathrm{D}$ \\
5. & Jam 9 kote' ngana pe jam pulang kantor? & $\mathrm{M} \longrightarrow \mathrm{F}$ \\
6. & Kase abis jo tare kwa' tu aer di bak, dari & $\mathrm{F} \longrightarrow \mathrm{S}$ \\
\hline
\end{tabular}




\begin{tabular}{|c|c|c|}
\hline & Papa nda mo mandi! & \\
\hline 7. & Kiapa kwa' sopulang? & $\rightarrow \mathrm{D}$ \\
\hline 8. & $\begin{array}{l}\text { Barmaeng HP jo terus kong nanti Mama } \\
\text { yang cuci tu piring! }\end{array}$ & \\
\hline 9. & No nanti mandi tenga malam jo dang ngana! & M \\
\hline 10. & Iyo kong bonceng kasana tiga orang! & $\mathrm{F}$ \\
\hline 11. & $\begin{array}{l}\text { Talalu capat ngana da angka ni ubi, sadiki } \\
\text { akangle kwa'! }\end{array}$ & \\
\hline 12. & Talalu banya doi kwa ngana pe papa & M \\
\hline 13. & Biar jo dang Ma kita pake HP rusak & $\mathrm{D}$ \\
\hline 14. & He, nonton-nonton jo sampe pagi! & $\mathrm{F}$ \\
\hline 15. & Hape hape jo kong jang belajar! & $\mathrm{F}$ \\
\hline 16. & Nanti mo belajar dang kalu ada peer? & \\
\hline 17. & Ta pe doi SPP so ciri di jalang & \\
\hline 18. & Nanti mandi kwa'jam 7! & \\
\hline 19. & Kong sadiki jotu nasi ngana da taru & \\
\hline 20. & Masojo tare' kwa' ditelevisingana! & \\
\hline 21. & He, so bagus ngoni dua bakuambe bagitu! & \\
\hline 22. & Mama kase jo sатиа pa Ade! & \\
\hline 23. & Pigi jo lebe dulu ngana nanti kita nae ojek! & M \\
\hline 24. & $\begin{array}{l}\text { Pe rapi skali ngana petampa tidor e, Papa suka } \\
\text { motidor akangtare, }\end{array}$ & \\
\hline 25. & $\begin{array}{l}\text { Talalu licing komang ngana da setrika ini ta pe } \\
\text { kemeja no }\end{array}$ & \\
\hline 26. & Nda bagarang tu dabu-dabu ta da rasa & $\mathrm{F}$ \\
\hline 27. & $\begin{array}{l}\text { Kita-kita jo dang terus tu Papa suruh-suruh, } \\
\text { kong Kakak nda usa }\end{array}$ & \\
\hline 28. & Iyo, dari kita katu' kwa' nda perlu laptop & S \\
\hline 29. & Nga pe jongos kita kang? & $\mathrm{D}$ \\
\hline 30. & Talalu pelang ngana pe suara De' & $\mathrm{D} \longrightarrow \mathrm{S}$ \\
\hline
\end{tabular}

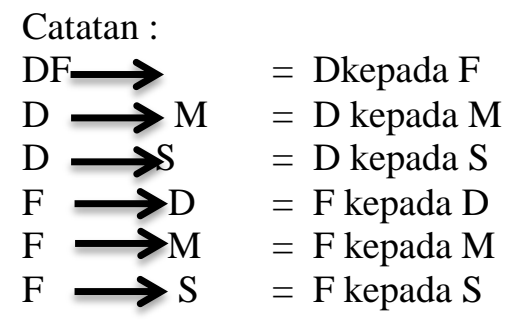

\section{Makna Tindak Tutur Langsung tidak Literal}

(1) So itu kwa'bangun lat !

'Sebab itu (Part.Pngs)bangun terlambat! 'Makanya bangunlah kesiangan!'

Tuturan (1) merupakan tuturan $\mathrm{M}$ kepada $S$ dan D karena merasa terganggu dengan keributan $\mathrm{S}$ dan $\mathrm{D}$ yang berebutan masuk kamar mandi. Tuturan M ini untuk

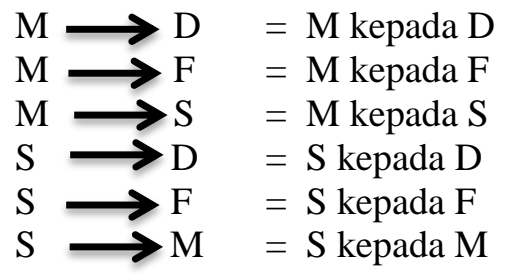

menyuruh $\mathrm{S}$ dan Dagar bangun lebih awal, bukan bermaksud menyuruh mereka bangun kesiangan.

(2) Iyo, manyao kamari ngana pa Mama!

'Iya, menyahut kemari kau pada Ibu!'

'Iya, berkomentarlah kau kepada Ibu!'

Tuturan (2) merupakan tuturan M secara keras untuk menyuruh D diam, 
ketika M sedang berbicara,bukan menyuruh mengomentari tuturan $\mathrm{M}$.

(3) Nda' mo mandi ngoni?

'Tidak akan mandi kalian?

'Kalian tidak akan mandi ?

Tuturan (3) disampaikan F kepada $\mathrm{S}$ dan $\mathrm{D}$ ketika melihat mereka masih saja menonton televisi padahal sudah waktunya mandi untuk bersiap pergi ke sekolah. $\mathrm{F}$ bukan menanyakan apakah $\mathrm{S}$ dan D tidak akan mandi tetetapi sebenarnya menanyakan mengapa mereka belum juga mandi.

(4) Iyo, tidor-tidorjo nanti sosapu malayang!

'Ya, tidur-tidur (Part.Pngs) nanti sapu melayang'

'Ya, tidur sajalah nanti dipukul dengan sapu'

Tuturan (4) disampaikan M kepada D ketika memanggilnya tetapi tidak kunjung keluar dari kamarnya. M bukan menyuruh $\mathrm{D}$ untuk tetap berbaring dan tidur, tetapi memerintahkan D segera bangun karena $\mathrm{M}$ ingin menyuruhnya pergi ke warung membeli minyak tanah. Jika D tidak bangun dan pergi, maka $\mathrm{M}$ akan memukulnya dengan sapu lidi.

(5) Jam 9 kote' ngana pe jam pulang kantor?

'Pukul 9 (Part.Pngs) kau punya waktu pulang kantor?

'Rupanya pukul 9 waktumu pulang kantor?

Tuturan (5) disampaikan M kepada F ketika F pulang kantor pukul 9 malam, padahal biasanya $\mathrm{F}$ pulang pukul 5. Jadi $M$ sebenarnya bertanya mengapa $F$ tidak pulang pukul 5 .

(6) Kase abis jo tare kwa' tu aer di bak, dari Papa nda mo mandi!

'Kasih habis (Part.Pngs)itu air di bak, dari Papa tidak akan mandi !'

'Habiskan saja air di bak, karena Papa tidak akan mandi !'

Tuturan (6) merupakan tuturan $\mathrm{F}$ kepada $\mathrm{S}$ yang sedang mandi. Tuturan $\mathrm{F}$ ini sebenarnya bukan untuk menyuruh $S$ menghabiskan air di bak, tetapi untuk menyuruh $\mathrm{S}$ agar menghemat air, karena $\mathrm{F}$ juga akan mandi. Waktu itu air dari PAM mati.

(7) Kiapa kwa'so pulang ?

'Mengapa (Part.Pngs) sudah pulang?'

'Mengapa sudah pulang ?'

Tuturan (43) disampaikan $\mathrm{M}$ kepada D yang baru saja pulang dari sekolah pada pukul 5 sore.Seharusnya D tiba di rumah sekitar pukul 1 siang.Tuturan $\mathrm{M}$ ini sebenarnya bertanya mengapa baru pulang untuk menunjukkan kepada $\mathrm{D}$ bahwa $\mathrm{M}$ marah.

(8) Barmaeng HP jo terus kong nanti Mama yang cuci tu piring!

'Bermain HP (Part.Pngs) terus lalu nanti Mama yang cuci itu piring!'

'Bermain HP saja terus lalu tidak usah cuci piring !'

Tuturan (8) disampaikan M kepada D yang disuruh $\mathrm{M}$ untuk mencuci piring tetapi tidak dilaksanakan. Tuturan $M$ ini untuk menghentikan D yang sedang bermain dan menyuruh $\mathrm{D}$ segera mencuci piring bukan mengijinkannya main HP dan nanti $\mathbf{M}$ yang akanmencuci piring.

(9) No nanti mandi tenga malam jo dang ngana!

'(Part.Pngs) nanti mandi tengah malam saja (Part.Pngs) kau !'

'Kalau begitu nanti saja kau mandi tengah malam !'

Tuturan (57) disampaikan M kepada $\mathrm{S}$ untuk menunjukkan kepada $\mathrm{S}$ bahwa $\mathrm{M}$ sebenarnya tidak suka $\mathrm{S}$ mandi malam hari.Jadi tuturan ini sebenarnya bukan untuk menyuruh $\mathrm{S}$ mandi tengah malam.

(10) Iyo kong bonceng kasana tiga orang !

'Iya lalu bonceng kesana tiga orang !'

'Iya lalu bonceng saja tiga orang!'

Tuturan (10) merupakan tuturan F kepada $\mathrm{S}$ bukan untuk menyuruh tetapi sebaliknya melarang $\mathrm{S}$ membonceng tiga orang.

(11)Talalu capat ngana da angka ni ubi, sadiki akang le kwa

'Terlalu cepat kau ada angkat ini ubi, sedikit (Part.Pngs) 
'Terlalu cepat kau masak ubi ini, tunggu sedikit lagi'

Tuturan (11) merupakan tuturan $\mathrm{F}$ kepada M ketika hendak makan ubi goreng buatan $\mathrm{M}$ namun ternyata hangus.Jadi $\mathrm{F}$ bukan bermaksud menyuruh $\mathrm{M}$ agar membiarkan ubi digoreng agak lama.

(12)Talalu banya doi kwa ngana pe papa

'Terlalu banyak uang (Part.Pngs) kau punya ayah'

'Terlalu banyak uang ayahmu'

Tuturan (11) merupakan tuturan M kepada D yang merengek-rengek dibelikan HP baru.Tuturan ini bermaksud memberi tahu bahwa ayah tidak punya cukup uang, bukan terlalu banyak uang.

(13) Biar jo dangMa kita pake hape rusak

'Biar (Part.Pngs) Bu kita pakai HP rusak'

'Biar saja Bu saya pakai HP rusak'

Tuturan (11) disampaikan D menanggapi tuturan M (12) untuk menegaskan bahwa dia tidak mau Hpnya rusak bukannya bersedia menggunakan HP rusak.

(14) He, nonton-nonton jo sampe pagi!.

'He, nonton-nonton (Part.Pngs) sampai pagi !'

'He, nonton saja sampai pagi !'

Tuturan (14) disampaikan $F$ kepada $\mathrm{S}$ dan $\mathrm{D}$ yang masih menonton televisi pada sabtu malam pukul 11.Sebelumnya semua sudah sepakat untuk pergi ke ibadah subuh di gereja pada besok hari.Tuturan $\mathrm{F}$ ini sebenarnya ingin menyuruh $\mathrm{S}$ dan $\mathrm{D}$ untuk segera berhenti nonton televisi, bukan menyuruh nonton sampai pagi.

(15) Hape hape jo kong jang belajar!

'HP HP (Part.Pngs) lalu jangan belajar!'

'HP saja terus lalu jangan belajar!'

Tuturan (15) merupakan tuturan $\mathrm{F}$ kepada D untuk menyuruhnya belajar bukan untuk menyuruhnya bermain HP.
(16) Nanti mo belajar dang kalu ada peer ?

'Nanti akan belajar (Part.Pngs) kalau ada PR'

'Nanti belajar kalau ada PR ?'

Tuturan (16) disampaikan M kepada D untuk memastikan jika belajar merupakan kewajiban, bukan nanti ada PR baru belajar.

(17) Ta pe doi SPP so ciri di jalang

'Kita punya uang SPP sudah ciri di jalan'

'Uang SPP saya jatuh di jalan'

Tuturan (17) merupakan pernyataan $\mathrm{S}$ kepada $\mathrm{F}$ bahwa uang yang diberikan F sebenarnya tidak jatuh, karena $\mathrm{S}$ sedang memegang bukti pembayaran SPP. Hal ini diungkapkan untuk menggoda $\mathrm{F}$ ketika memberikan uang kepada $\mathrm{M}$.

(18) Nanti mandi kwa' jam 7 ! 'Nanti mandi (part.penegas) pukul 7 $!$

'Mandi nanti saja pukul 7 !

Tuturan (18) disampaikan M kepada $\mathrm{D}$ yang mengambil handuk untuk mandi.Tuturan $M$ sebenarnya untuk mengingatkan D agar jangan mandi pukul 7 dimana tidak lama lagi harus pergi beribadah.

(19) Kong sadiki jo tu nasi ngana da taru

'Lalu sedikit (Part.Pngs) itu nasi kau ada taruh'

beri !'

'Betapa sedikitnya nasi yang kau

Tuturan (19) merupakan tuturan F kepada $\mathrm{M}$ untuk menyatakan bahwa terlalu banyak nasi yang diberikan, bukan terlalu sedikit ataupun bermaksud meminta tambah nasi.

(20) Masojo tare 'kwa'di televisi ngana!

'Masuk (Part.Pngs) di televisi kau !'

'Masuk saja di televisi kau !'

Tuturan (20) merupakan tuturan $\mathrm{S}$ kepada $\mathrm{D}$ yang sedang menonton televisi dengan jarak yang sangat dekat, sehingga $\mathrm{S}$ tidak dapat menonton dengan baik.S ingin agar $\mathrm{D}$ menyadari bahwa $\mathrm{D}$ 
menghalangi layar televisi dan sekaligus menyuruh D untuk mengambil jarak lebih jauh dari depan televisi.

(21) He, so bagus ngoni dua bakuambe bagitu

'He,sudah bagus kalian dua saling ambil begitu'

'He, baik sekali kalian berdua bertengkar seperti itu'

Tuturan (21) merupakan tuturan M kepada $S$ dan $D$ yang terus bertengkar.Tuturan ini bukan memuji pertengkaran mereka, namun mengingatkan bahwa tidak baik bertengkar.

(22) Mama kase jo samua pa Ade'!

'Ibu beri (Part,Pngs) semua pada Adik'

'Ibu beri saja semuanya kepada Adik

Tuturan (22) merupakan tuturan S kepada $\mathrm{M}$ yang membeli kue tetapi yang pertama diberi yaitu D. Ketika tinggal beberapa potong baru ditawarkan kepada $\mathrm{S}$. Tuturan ini mau menyatakan bahwa $\mathrm{S}$ juga mau kue, dan jangan diberikan semuanya kepada D.

(23) Pigi jo lebe dulungana, nanti kita nae ojek jo!

'Pergi (Part.Pngs) lebih dulu kau , nanti kita naik ojek(part.Pngs)!

'Pergi saja duluan, nanti saya naik ojek saja!

Tuturan (23) merupakan tuturan M kepada $\mathrm{F}$ yang terus-menerus memanggil $\mathrm{M}$ untuk segera berangkat ke pesta karena F sudah siap.Sebenarnya M tidak menyuruh $\mathrm{F}$ untuk berangkat lebih dulu dan $M$ nanti naik ojek saja tetapi menyuruh $\mathrm{F}$ menunggu, karena $\mathrm{M}$ tidak mau naik ojek.

(24) $\mathrm{Pe}$ rapi skali ngana pe tampa tidor e, Papa suka mo

'Begitu rapi sekali kau punya tempat tidur (Part.Pngs) Ayah suka akan tidor akang tare'

tidur (Part.Pngs)'

'Rapi benar tempat tidurmu, Ayah ingin tidur'
Tuturan (24) disampaikan F kepada S ketika masuk ke kamar tidur D dan melihat tempat tidurnya yang acakacakan.Jadi F bukan memuji S.

(25) Talalu licing komang ngana da setrika ini ta pe kemeja

'Terlalu licin (Part.Pngs) kau ada seterika ini ku punya kemeja

no

(Part.Pngs)'

'Terlalu licin kemejaku yang kau seterika'

Tuturan (25) disampaikan $\mathrm{F}$ kepada $M$ ketika melihat kemeja yang akan dipakainya ke kantor sangat kusut, bukan mengatakan terlalu licin.

(26) Nda bagarang tu dabu-dabuta $d a$ rasa

'Tidak bergaram itu sambalku ada rasa'

'Sambal tidak bergaram, saya sudah mencicipinya'

Tuturan (26) ini disampaikan $\mathrm{F}$ ketika mencicipi sambal yang dibuat terasa pahit sekali karena kebanyakan garam. Jadi $\mathrm{F}$ bukan menyatakan bahwa sambal tidak bergaram.

(27) Kita-kita jo dang terus tu Papa suruh-suruh, kong Kakak nda usa

'Kita-kita(Part.Pngs) terus itu Ayah suruh-suruh, lalu Kakak tidak usah'

'Saya saja yang terus disuruh, lalu Kakak tidak usah'

Tuturan (27) disampaikan D kepada F ketika F menyuruhnya menampung air di bak, sedangkan kakaknya hanya menonton televisi. Dalam hal ini D meminta $F$ agar menyuruh sang kakak, bukan dirinya yang selalu menampung air di bak.

(28) Iyo, dari kita katu'kwa' nda perlu laptop

'Iya, dari kita(Part.Pngs) tidak perlu laptop'

'Ya, saya memang tidak memerlukan laptop'

Tuturan ini disampaikan S ketika meminta laptop yang dipinjam $\mathrm{D}$, tetapi $\mathrm{D}$ tetap asyik main game di laptop. $\mathrm{S}$ 
sebenarnya mengatakan bahwa $\mathrm{S}$ perlu laptop untuk membuat tugas dari guru.

(29) Nga pe jongos kita kang?

'Kau

punya pembantu

kita(Part.Pngs)?

'Saya memang pembantumu?'

Tuturan (29) ini disampaikan D

kepada $S$ yang menyuruhnya mencuci motor. D bermaksud meyakinkan bahwa dirinya memang bukan pembantu, bukan benar-benar pembantu.

(30) Talalu pelang ngana pe suara De'

'Terlalu pelan kau punya suara Dik'

'Suaramu terlalu pelan suaramu, Dik'

Tuturan (30) disampaikan D kepada $\mathrm{S}$ yang sedang bernyanyi dengan suara yang sangat keras sehingga D merasa terganggu karena sedang belajar. Jadi bukan mengatakan suara D terlalu pelan.

Catatan $:($ Part.Pngs $)=$ Partikel Penegas

Berdasarkan pada temuan hasil penelitian, maka dapat dikemukakan keterkaitannya dengan teori-teori yang menjadi landasan sesuai dengan urutan permasalahan dan tujuan penelitian yang telah ditetapkan sebelumnya.

\section{Bentuk-bentuk Tindak Tutur Langsung Tidak Literal pada Keluarga Batih yang berbahasa Melayu Manado.}

Berdasarkan 30 tindak tutur langsung tidak literal BMM, maka dapat dikatakan bahwa bentuk-bentuk tindak tutur langsung tidak literal pada keluarga Batih yang berBMM muncul dalam bentuk kalimat perintah, seperti pada tuturan (1) Soitukwa' bangun lat! (2)Iyo, manyao kamari ngana pa Mama! (4)Iyo, tidor-tidor jo nanti sosapu malayang! (6) Kase abis jo tare kwa' tu aer di bak, dari Papa nda mo mandi!(8) Barmaeng HP jo terus kong nanti Mamayang cuci tu piring!(9)No nanti mandi tenga malam jo dang ngana !(10) Iyo kong bonceng kasana tiga orang!(11) Talalu capat ngana da angka ni ubi, sadiki akangle kwa'!(14)He, nontonnonton jo sampe pagi !(15)Hape hape jo kong jang belajar! (18) Nanti mandi kwa' jam 7 !(20) Masojo tare' kwa' ditelevisingana!(21)He, so bagus ngoni dua bakuambe bagitu !(22)Mama kase jo samua pa Ade!(23)Pigi jo lebe dulu ngana nanti kita nae ojek!, kalimat berita, seperti pada tuturan (12) Talalu banya doi kwa ngana pe papa (13)Biar jo dang Ma kita pake HP rusak(17) Ta pe doi SPP so ciri di jalang(19) Kong sadiki jotu nasi ngana da taru(24) Pe rapi skali ngana petampa tidor $e$, Papa sukamo tidor akang tare'(25)Talalu licing komang ngana da setrika ini ta pe kemeja no(26) Nda bagarang tu dabu-dabu ta da rasa (27)Kita-kita jo dang terus tu Papa suruhsuruh,kong Kakak nda usa (28)Iyo, dari kita katu' kwa' nda perlu laptop (30)Talalu pelang ngana pe suara De', dan kalimat tanya seperti pada tuturan (3) $N d a^{\prime}$ mo mandi ngoni ?(5) Jam 9 kote' ngana pe jam pulang kantor ?(7) Kiapa kwa' sopulang ?(16)Nanti mo belajar dang kalu ada peer? (29)Nga pe jongos kita kang?

\section{Cerminan Tindak Tutur Langsung Tidak Literal pada Keluarga Batih yang Berbahasa Melayu Manado}

Tuturan-tuturan BMM yang muncul menunjukkan relasi di antara sesama anggota keluarga Batih : relasi S dan $\mathrm{D}$ dengan $\mathrm{F}$ dan $\mathrm{M}, \mathrm{F}$ dengan $\mathrm{M}$, di antara sesama $\mathrm{S}$ dengan $\mathrm{D}$. Cerminan relasi juga nampak dalam penggunaan kata "ngana/nga" (terutama) dan "kita/ta", serta penggunaan istilah kekerabatan. Hal ini dikarenakan penggunaan kata-kata tersebut dalam BMM hanya berlangsung dalam relasi akrab/atau sangat dekat antara penutur dan mitra tutur ; dalam hal ini, relasi yang paling akrab yaitu dalam keluarga Batih. Penutur selalu akan menggunakan kata "kita" untuk menggambarkan dirinya (ego) dan kata "ngana" hanya kalau relasi ego dengan mitra tutur ini bersifat egaliter. 
Dilihat dari segi sapaan nampak jelas adanya bentuk relasi yang bersifat egaliter di antara Ayah dan Ibu (FM), dan di antara anak-anak (S $\rightleftarrows$ D). Relasi yang bersifat egaliter nampak dalam penggunaan kata "kita/ta" pada tuturan (13) (26) (27) (28) (29) dan kata "ngana/nga" pada tuturan (5) (9) (11) (17) (19) (20) (22) (23) (24) (25) (29) (30) Penggunaan kata "ngana/nga" juga hanya sebatas anak dengan anak, atau antara ayah dengan ibu, ayah dengan anak, serta ibu dengan anak, sedangkan anak dengan ayah mau pun ibu dianggap tidak sopan.

Penggunaan istilah kekerabatan menunjukkan relasi yang bersifat hierarkhi antara orang tua kepada anak, serta antara kakak dan adik.Relasi yang bersifat hierarkhis nampak pada tuturan (2) (6) (8) (12) (24) (27) (30). F dan M terhadap $\mathrm{S}$ mau pun $\mathrm{D}$ tidak menggunakan kata "kita/ta" sebagai ego tetapi menggunakan istilah kekerabatan (nama status) untuk menjaga wibawa mereka dan agar dihormati sebagai orang yang lebih tinggi kedudukannya dalam keluarga.

\section{Kecenderungan orang Manado lebih mengedepankan relasi egaliter sehingga kalimat tanya diutarakan secara langsung tidak literal.}

\section{SIMPULAN DAN SARAN}

Merujuk pada hasil dan pembahasan penelitian di atas, maka peneliti menarik beberapa simpulan berdasarkan permasalahan dan tujuan penelitian di antaranya yaitu: 1) tindak tutur langsung tidak literal pada keluarga Batih yang berbahasa Melayu Manado dituturkan dalam bentuk kalimat perintah,kalimat berita, begitu pun kalimat tanya; 2) makna bawaan yang secara implisit ada dalam setiap tuturan cepat dimengerti oleh setiap anggota keluarga baik yang bertindak sebagai penutur mau pun mitra tutur. Semua ini dikarenakan karena adanya proses habitualisasi yang terjadi dalam keluarga Batih yang memiliki jarak sosial yang paling dekat; 3) tindak tutur langsung tidak literal pada keluarga Batih yang berBMM dilakukan dalam relasi bersemuka dan mencerminkan dua corak relasi di antara anggota keluarga yaitu relasi egaliter antara anak lelaki $($ Son $=\mathrm{S})$ dengan anak perempuan (Daughter $=\mathrm{D})$, ayah $($ Father $=\mathrm{F})$ dengan ibu (Mother $=$ $\mathrm{M})$, serta relasi hirarkhis antara orangtua (Parents $=\mathrm{F}+\mathrm{M})$ dengan anak-anak (Children $=\mathrm{S}+\mathrm{D})$. Sekaitan dengan simpulan hasil penelitian, peneliti menyarankan agar hasil penelitian ini dapat dikembangkan dengan cara memperluas populasi dalam jenis tindak tutur yang lain dikarenakan penelitian ini merupakan suatu kajian atau studi kasus.

\section{UCAPAN TERIMA KASIH}

Peneliti patut menyampaikan terima kasih kepada semua pihak yang telah membantu pelaksanaan riset ini yaitu Prof. Dr. M. Salea Warouw, MS, Dr. Paul Richard Renwarin, Ibu Nonie Kolondam, Tonny Dj. Ratuela, SE, Gilbert J. Ratuela, Hillary S. P. Ratuela. Ucapan terima kasih juga disampaikan kepada Dewan Redaksi Jurnal bahasa \&sastra Fakultas Pendidikan Bahasa dan Seni Universitas Pendidikan Indonesia yang telah membantu dalam memublikasikan artikel ini.

\section{PUSTAKA RUJUKAN}

Chaer, A.2007. Kajian Bahasa : Struktur Internal, Pemakaian dan Pemelajaran. Jakarta : Rineka Cipta.

Cummings, L.2007. Pragmatics : A Multidisciplinary Perspective. Editor: Prof. Dr. Abdul Syukur Ibrahim. Penerjemah Eti Setiawati, dkk. Yogyakarta : Pustaka Pelajar.

Moleong,L,J.2007. Metodologi Penelitian Kualitatif. Bandung : PT Remaja Rosdakarya. 
Nadar, F.X.2009. Pragmatik \& Penelitian

Pragmatik.Yogyakarta : Graha Ilmu

Stake. 2009. Studi Kasus dalam Denzin, Norman, K dan Yvonna S. Lincoln (Eds.) Handbook of Qualitative Research. Edisi Bahasa Indonesia. Yokyakarta : Pustaka Pelajar.

Sudaryanto.1993. Metode dan Aneka Teknik Analisis Bahasa.

Yogyakarta: Duta Wacana University Press.

Tallei, H.L.2007. Interseksi antara Aspektualitas dan Temporalitas dalam Bahasa Melayu Manado. Tesis. Manado : Program Pascasarjana UNSRAT.

Trudgill, P.2003. A Glossary of Sociolinguistics. George Square, Edinburgh : Edinburgh University Press.

Wijana,I.D.P.1996.Dasar-dasar

Pragmatik. Yogyakarta : Andi 